An Investigation of the Production of... العدد الثامن والثلاثون

\title{
An Investigation of the Production of English Intonational Patterns by South Sinai Bedouin Arabic Speakers.
}

\author{
A research Submitted By: \\ Norhan Amr Nabil Abougrisha \\ Suez Canal University \\ Faculty of Arts and Humanities \\ nourhan.greisha@art.suez.edu.eg
}

\begin{abstract}
:
The same word or utterance could be said in different ways or using different intonational patterns to deliver different meanings and attitudes. The purpose of this study is to investigate the kinds of misunderstandings caused by the intonational patterns used by non-native speakers of English. The subjects of the study are Egyptian Bedouins living in Dahab in South Sinai. The theories of David Crystal and Peter Roach regarding intonation are the main theories used in the analysis. This research is an attempt to discover the intonational patterns produced by non-native speakers of English and to see to what extent they are distant from the patterns produced by native speakers of English. The utterances of the non-natives are divided and


the intonational patterns are studied by a jury that consists of five highly educated native speakers of English language. The data is analyzed qualitatively and quantitatively and the results are presented in percentage and graphs.

Key words: Tone, Intonation, Native speakers, Peter Roach, Dahab.

\section{Introduction:}

The way we produce utterances can really affect the meaning. With the same set of words we can deliver several meanings, attitudes and emotions. Our topic here is investigating the different patterns of intonation that nonnatives use while speaking English. The non-natives whose utterances are being investigated are Bedouins living in Dahab, South Sinai, Egypt. Dahab is a small city and is like a melting pot for many cultures and languages; it attracts a lot of tourists because of the amazing nature and magnificent diving sites. Bedouins mainly work in tourism and are in contact with many tourists every day.

As a result of Dahab being a touristic spot for divers and nature lovers many languages are used for communication. Both tourists and Bedouins speak English language to communicate with each other. Consequently, the intonational patterns they use when they speak English may cause a problem in communication; inaccurate intonation may cause misunderstanding. 
The following example shows how the use of different intonation patterns/tones changes the meaning of the whole utterance, though the utterance consists of the same lexical item(s):

She gave her dog 'biscuits $=$ (she gave her dog some biscuits).

She gave her 'dog biscuits = (she gave the dog biscuits to someone).

In this example, we see how a shift in tonic syllable results in a change in the meaning of the whole utterance.

Bedouins use different intonation patterns from native speakers of English. The usage of these different intonation patterns causes or leads to some misunderstandings between native and non-native speakers. Our research is comparing and contrasting the intonation patterns used by the Bedouins and those used by native speakers of English. We aim to find the similarities and differences between both and to find the reasons behind these differences.

To conduct such a study, the previous studies concerning our topic are reviewed and some theories of intonation are presented. The data is collected by recording short utterances and conversations spoken by Bedouins. The data analysis is conducted from a perceptual perspective by the aid of a jury. In order to answer the research questions 
posed in this study, the results are presented quantitatively and qualitatively.

\section{Aim of the study:}

Speakers frequently mean much more than their words actually mean. As a matter of fact, people can mean something quite different from what their words express, or even just the opposite. When long pattern of intonation is being used when conveying a certain message a great amount of misunderstanding is created which may cause problems. This drives the researcher to the idea of investigating the mechanisms which help a speaker reveal his ideas and intentions so as to reach his communicative objectives successfully when communicating with others.

The researcher presents the data she collects, how they are collected and how she intends to analyze them. There is also a reference to the methods adopted in the analysis and the premises and assumptions to be tested.

\section{Research problem:}

Different patterns of intonation indicate different attitudes and denote several meanings. To deliver certain information and to express the right or suitable attitude a convenient pattern of intonation must be used. In other words, the matter here is not what non-native speakers of English say but how they say it and to what extend it is matching the way native speakers of English speak. 
Bedouins working in tourism services speak more than one foreign language in addition to their first language (L1).As for English, stress patterns and intonation may be affected mainly by their native language or their South Sinai Arabic Bedouin dialect.

This may result in misunderstanding among tourists whose first language and sometimes second language is English. This research is an attempt to discover changes in intonational patterns to see to what extent they are distant from the patterns produced by native speakers of English. The similarities and differences in the intonational patterns of non-native speakers' utterances are studied.

\section{Research questions:}

1- Are there any differences between the patterns of intonation of native speakers of English compared to nonnative speakers' patterns?

2- What are the sources of errors in intonation patterns produced by Bedouins?

3-What kind of misunderstanding may result from misusing the intonation patterns?

\section{The literature review:}

Obviously, the everyday Arabic language has a huge diversity in Egypt, this is because the multi-ethnic variety of dialects spoken by the people all over Egypt. For example, South Sinai Bedouin tribes' pronunciation is different from 
other Egyptian people and even from other Bedouins in North Sinai, New Valley, and Marsa Matroh. Hence, South Sinai Bedouin tribes' dialect has a distinguished pronunciation, intonation, grammar and vocabulary. Bedouins of this area have a swift and skillful command over their Bedouin dialect when speaking to a Bedouin and their Arabic when speaking to others.

In this sense, each tribe has a different dialect with its peculiar vocabulary. In fact, South Sinai Bedouins have a domain over two dialects. South Sinai Bedouins' intonation is the main target of this study. Thus, this research tackles the patterns of the intonational system in South Sinai Bedouins speaking English. Previous researches into intonation, Bedouins' dialects and/or South Sinai Bedouins may be useful, insightful, and informative to this research.

The following are some of the studies on intonation conducted in bilingual contexts. It is worth mentioning that some of these studies motivated the researcher to complete research in this area.

According to Tench (2005) the importance of studying intonation can be summarized in three main points. Firstly, intonation shows the speakers' perception of the organization of their information both experientially and textually; secondly, it shows the interpersonal dimension in types of communication; and thirdly, it shows the speaker's attitude accompanying the message. 
An intonation unit, whether in neutral or marked tonality, has one obligatory component, the tonic segment. This contains the most prominent stress (= tonic syllable) and carries the most significant pitch movement of the whole unit.

In a study conducted by verdugo (2002) it has been observed that native speakers express the difference in the status of information within a speech function by the choice of tone. A falling tone reflects new information, while a low rise denotes given information. Non-native speakers do not express such contrast by their choice of tone. They avoid the use of a low-rise tone to express minor or given information, overusing a falling tone.

\section{The theoretical framework:}

\subsection{Phonological Features and definitions:}

The research is studying phonology on a suprasegmental level. Definitions and theories regarding the field of the study are presented in this section. In other words the researcher is concerned with stress, tones and intonation.

“The notions 'stress', 'tone', 'accent', and 'intonation' all refer to supra-segmental aspects of the phonological structure, but they are in fact rather different. Many phonologists would argue that all languages have phonological stress in the sense of foot structure, even though the phonetic salience of stressed syllables will vary considerably from language to language, to the extent that 
some languages have no observable phonetic stress." (Carlos Gussenhoven The Phonology of Tone and Intonation. 2004 . page 12 )

The tone and intonation is the master player in the study, how they are used and what messages they convey are the main concern of the study. The use of different tones, when producing or when uttering the same word, delivers different messages or different attitudes to the listener. Tones play with the inferred meaning or the deep meaning of words. "Tone and Intonation are two types of pitch variation, which are used by speakers of many languages in order to give shape to utterances. More specifically, tone encodes morphemes, and intonation gives utterances a further discoursal meaning that is independent of the meanings of the words themselves." (Carlos Gussenhoven The Phonology of Tone and Intonation . 2004 - page i )

"Tone and Intonation are two types of pitch variation, which are used by speakers of many languages in order to give shape to utterances. More specifically, tone encodes morphemes, and intonation gives utterances a further discoursal meaning that is independent of the meanings of the words themselves." ( Carlos Gussenhoven The Phonology of Tone and Intonation . 2004 . page i )

The pitch is simply the vibration of the vocal cords. The more the vibration takes place the more the pitch gets 
higher. This vibration happens within the vocal cords in the air passage, in other words, the vocal tract.

"The pitch of the voice is determined by several factors. The most important is the tension of the vocal folds. If the vocal folds are stretched, the pitch of the sound will go up. Altering the tension of the vocal folds is the normal way of producing most of the pitch variations that occur in speech." (Ladefoged and Johnson 2011 - A course in phonetics - page 254).

The change in the pitch creates different tones. The movement of the pitch from one tone to another one makes a variety of tones. "Pitch variations that affect the meaning of a word are called tones." (Ladefoged and Johnson 2011 A course in phonetics - page 255). The movement from a low pitch to a higher one creates a rising tone. The movement from a higher pitch to a lower creates a falling tone. The movement from a high pitch to a lower one then back to a high pitch again is creates falling rising tone. The movement from a low pitch to higher one then back to a low one again is called rising falling tone. Staying still in the same pitch level without movement creates level tone. "The pitch pattern in a sentence is known as the intonation." (Laedefoged and johnson . 2011.6 ${ }^{\text {th }}$ ed. A course in phonetics - page 24).

This study is mainly concerned with intonation, the tones and the changes in the tones and what misunderstandings that may result out of this change. The 
different tones used in speech or conversation deliver different meanings or attitudes and feelings. As commonly said it's not what you say it's how you say it. The different tones is created when there is a change in the pitch. "The intonation of a sentence is it's pattern of pitch changes. The part of a sentence over which a particular pattern extends is called an intonational phrase." (Laedefoged and johnson . $2011.6^{\text {th }}$ ed. A course in phonetics - page 118).

Different tones in English like (falling, rising, risingfalling, falling-rising and level) are created by a change in the pitch and used to convey different messages and express different feeling and attitudes. "Tone and Intonation are two types of pitch variation, which are used by speakers of many languages in order to give shape to utterances. More specifically, tone encodes morphemes, and intonation gives utterances a further discoursal meaning that is independent of the meanings of the words themselves." ( Carlos Gussenhoven The Phonology of Tone and Intonation . 2004 - page i )

People are, possibly, more aware of intonation's use in communicative functions, because they have to respond to them in an appropriate way, but people are most aware of the attitudinal function of intonation, because it tells them something about the person who is speaking (Tench, 1996: 107). This saying goes typically with main aim of the research, as the researcher is investigating the topic in the light of attitudinal function of intonation. 
Though some linguists have thought of intonation's role in expressing attitude as being additional, many of the best-known descriptions of English intonation have regarded the attitudinal function as primary and central, notably Pike (1945), Halliday (1967), Crystal (1969), O'Connor and Arnold (1973), Crystal (1975), Brown (1977), Brazil et al. (1980)and Ladd (1980). In this study, the researcher follows the same line of the above writers.

This study focuses mainly on the first function of intonation according to Peter Roach: the attitudinal function on intonation. The perceived message of what the speakers say is understood by the tones they use. The researcher is concerned with the meanings inferred or the deep meanings of words that is understood by means of tone and intonation.

One more point to add here is the fact which Roach (1992) states that "few people have actually done experiments on listeners' perception of attitudes through intonation." That is why the researcher chooses to investigate the topic of intonation from a perceptual point of view depending on the jury of native speaker of English language to analyze the collected data of non native speakers of English language.

Roach describes intonation as a linguistically significant change of voice pitch, i.e. the pitch change has to be perceptible and under the speaker's control (Roach 1991:133-134). Pitch is usually described as being 'high' or 'low' to varying extents, but it should be noted that in the 
context of intonation these terms only refer to the relative 'height' of pitch within the speaker's individual pitch range.

\section{Methodology:}

\subsection{Introduction:}

"A search for deeper explanations characterizes the last century research. Phonologists are now trained to ask why sound patterns are the way they are... Why do all languages make use of the same basic set of phonological features?" (Blevins, 2004). Following that perspective, besides the importance of intonation in conveying the speaker's intended meaning, the researcher is analyzing Bedouins regular intonations when speaking English, trying to reach a general conclusion of the differences between patterns of intonation used by Bedouins compared to natives and what kind of errors or misunderstandings may result from the misuse of the correct intonational pattern.

One more point to add here is the fact which Roach (1992) states that "few people have actually done experiments on listeners' perception of attitudes through intonation." That is why the researcher chooses to investigate the topic of intonation from a perceptual point of view depending on the jury of native speaker of English language to analyze the collected data of non native speakers of English language.

\subsection{Intonation... Why?}


"Phonetic laws and phonological rules were documented and formalized; phonetic and phonological features were identified and systematized; and sound correspondances between languages were used to formulate laws of sound change" (Blevins, 2004). However, as stated by Roach (1992),

"The attitudinal use of intonation is something that is best acquired through talking with and listening to English speakers." (p. 169). Thus, the researcher aims simply to shed light on a spot that makes people more aware of and sensitive to the way English speakers use intonation and how they perceive what non-native English speakers say. In addition to, what attitude does the native speaker understands from what Bedouins say and if that attitude is in accordance with the tone used. In other words, do Bedouins use the correct tones to covey what they want to say? Are they able to express their attitudes by means of tones and intonation? Are native speakers of English able to understand what Bedouins mean?

Moreover, "intonation makes it easier for a listener to understand what a speaker is trying to convey" (Roach, 1992, p. 163). Therefore, it contributes to the present study as it helps the researcher to figure out if there is any misunderstanding resulting from the intonation of Bedoiuns speeches and what really they are trying to convey in their speeches and how. 
One more point to add here is the fact which Roach (1992) states that "few people have actually done experiments on listeners' perception of attitudes through intonation." For instance, the experiments reported in Crystal (1969), are only small-scale pilot experiments. Uldall $(1960,1964)$ used a speech synthesizer to vary speech and elicit listeners' judgments.

Roach describes intonation as a linguistically significant change of voice pitch, i.e. the pitch change has to be perceptible and under the speaker's control (Roach 1991:133-134). Pitch is usually described as being 'high' or 'low' to varying extents, but it should be noted that in the context of intonation these terms only refer to the relative 'height' of pitch within the speaker's individual pitch range.

The first essential concept Roach uses in his description of intonation is that of an 'utterance', "a continuous piece of speech beginning and ending with a clear pause" (Roach 1991:134). An utterance consists of one or more 'tone-units', the borderlines of which are sometimes hard to determine. Often a return to a particular pitch level or a break of speech rhythm marks the beginning of a new tone unit, but these are only guidelines that do not always apply in natural speech (Roach 1991:159).

"The tone-unit can be further divided into 'pre-head' (the part before the first stressed syllable), 'head' (the part from the first stressed syllable of the tone-unit to the beginning of the tonic syllable), 'tonic syllable' and 'tail' (the 
part after the tonic syllable and before the end of the toneunit). The most important of these is the tonic syllable, which is usually perceived as having the highest degree of prominence of all stressed syllables in the tone-unit, because it carries the 'tone' of the tone-unit" (Roach 1991:145).

By 'tone' is meant the type of pitch movement that is performed in a particular tone-unit. Roach distinguishes between 5 different tones: 'fall', 'rise', 'level', 'fall-rise' and 'rise-fall'.

Level tones, i.e. tones in which the pitch stays on the same level for the whole of the tone-unit are not very common in English and are perceived as being unnatural (Roach 1991: 135), or expressing boredom. Falling tones, which descend from a higher to a lower pitch level, are much more frequently used in English and leave the perceiver with an impression of 'finality' (Roach 1991:138). A rising tone on the other hand gives an impression of openness, thus it typically occurs at the end of questioning utterances. Tone-units with a fall-rise tone are slightly less frequent, but commonly used in English to express an attitude that might best be described as a sense of "limited agreement". Quite rare is the rise-fall, often dubbed the "gossiping" tone, as it conveys a sense of surprise, or of intense approval or disapproval (Roach 1991:139).

For example, we can say a sentence in different ways, and depending on which intonation we choose, we might convey 'anger,' 'happiness,' 'boredom,' 'gratefulness' and so 
on. In general terms, a falling tone indicates finality; a rise a question or "more to follow"; a fall-rise uncertainty, doubt or a request; a rise-fall surprise. However, attitudes aren't conveyed by tones alone, as there are other variables that have as much an important role in communication as tones do. Peter Roach takes these variables into consideration and groups them into three types: sequential, prosodic and paralinguistic. In a nutshell, 'sequential' concerns the inner tone unit structure, pauses, and tone-unit boundaries; 'prosodic' relates components such as width of pitch range, key, loudness, speed and voice quality; finally, 'paralinguistic' has to do with facial expression, gesture and body movements.

As (Roach 2009:153) suggested, "To put it in the broadest possible terms, we can see that intonation makes it easier for a listener to understand what a speaker is trying to convey. The ways in which intonation does this are very complex, and many suggestions have been made for ways of isolating different functions. Among the most often proposed are the following:

i) Intonation enables us to express emotions and attitudes as we speak, and this adds a special kind of "meaning" to spoken language. This is often called the attitudinal function of intonation.

ii) Intonation helps to produce the effect of prominence on syllables that need to be perceived as stressed, and in particular the placing of tonic stress on a 
particular syllable marks out the word to which it belongs as the most important in the tone-unit. In this case, intonation works to focus attention on a particular lexical item or syllable. This has been called the accentual function of intonation.

iii) The listener is better able to recognize the grammar and syntactic structure of what is being said by using the information contained in the intonation; for example, such things as the placement of boundaries between phrases, clauses or sentences, the difference between questions and statements, and the use of grammatical subordination may be indicated. This has been called the grammatical function of intonation. iv) Looking at the act of speaking in a broader way, we can see that intonation can signal to the listener what is to be taken as "new" information and what is already "given", can suggest when the speaker is indicating some sort of contrast or link with material in another tone-unit and, in conversation, can convey to the listener what kind of response is expected. Such functions are examples of intonation's discourse function."

\subsection{Functions of Intonation:}

As suggested by Peter Roach (1992), the most often proposed functions of intonation are: the attitudinal function, the accentual function, the grammatical function and the discourse function these functions are explained in detail earlier in this chapter. This study mainly focuses on the attitudinal function of intonation. 
7.4 How to analyze the intonation of Bedouins speeches?

As "intonation is used to convey our feelings and attitudes" (Roach, 1992), the researcher adopts a very useful and realistic approach. She studies various recordings of Bedouins natural speech and tries to reach generalizations about how they express their attitudes and feelings by tones and intonation and do they use the correct tone to express their attitude. This adopted approach is judged by Roach (1992) as a much more useful and realistic than any other approach.

7.4.1 The criteria of selecting the phonological sample:

In order to be objective, the researcher considers the following criteria when deciding on the sample corpus:

The researcher tries to:

a) Select sentences or utterances that are clear and is heard effortlessly.

b) Select the middle part of the speech as a model so that the speaker is less likely to be stuttering, showing up or feeling exhausted.

c) Selecting material whose lexical meaning of the words used already makes the speaker's attitude pretty clear. 
d) Avoid certain vocal effects such as laughs and sobs as they do not come within the scope of this study.

e) Avoid whispered speech for "it is not possible to speak without one's speech having some degree or type of pitch range loudness, speed and voice quality," (Roach, 1992) and in whispered speech those pitch factors are largely lost.

f) Informing the participants that there is recording at some point (for the sake of honesty of course) but not telling them when in order to keep the spontaneity and avoid shyness or tension.

g) Samples or participants are selected from different ages and gender and educational background for the sake of generalization.

h) The audios cover two areas; participants speaking freely while other participants take part in conversations.

\subsubsection{Data:}

Data is collected by recording for Bedouins speaking English language. The length of the recording varies to cover more than one aspect. The spontaneity of the speech is a priority to the researcher in order to avoid any artificiality. Samples or case studies are from different ages, 
gender and social backgrounds to be able to cover a wide range of speakers.

\subsubsection{Methods of the study:}

1- Recording some samples for non-natives speaking English.

2- Analyzing these samples by the aid of a jury to make sure of the validity of the results. Questionnaires are used in the analysis to ensure a high rate of accuracy.

3- Denoting the differences and the similarities in samples. Analyze the use of tones and what attitudes and feelings do they express.

\subsubsection{Duration}

The duration of all utterances is approximately twenty (20) minutes. The duration varies from one speaker to the other. This variation keeps the spontaneity of the speech or the flow of the speech; some people have a lot to say while others may have a little to say. The researcher tries not to force the speakers or the participants to speak in order to avoid any stress and to keep things real and authentic.

\subsubsection{Participants}

The participants of the study are Bedouins living in Dahab city in South Sinai in Egypt most of them working on tourism and all of them are in contact with native speakers of English (tourists). The researcher tries to choose 
An Investigation of the Production of... العدد الثامن والثلاثون

different samples; both sexes are included in addition to different ages. There are five participants:

Mr. Radwan

Mariam

Khadija

Mohamed

Asmaa

\subsubsection{The Jury}

The jury consists of five highly educated native speakers specialized in English language. The participants of the jury listen to the utterances and fill into the questionnaire, they recognize the tones the Bedouin speakers produce and mention what feelings and attitudes they perceive as a hearer.

Kendra Macey, she is American. She works as an international English language and Montessori educator. She is also on her way to finish her masters specialized in English language.

Bridget Dangel, she is American. She works as an international English language and Montessori educator. She is also the manager and the owner of a school in Florida. 
Susan Adams, she is American. She works as an international English language educator.

Johania Burgan, she is American. She is an English teacher.

Anna Cameron, she is Australian. She is a master holder specialized in English language and she works as an English teacher.

A note to be added here is that two of the jury cooperated and fill in one questionnaire. Bridget Dangle and Susan Adams fill in one questionnaire together.

\subsubsection{The questionnaires}

The questionnaires are designed in the form of tables. Each table contains three columns; one for the utterances, the second for the tone and the third is for the attitude. Each speaker or participant has an individual table for his data or utterances. The utterances is chosen and divided in the first place by one of the jury "Kendra Macey". She listens to the audios and divided them into utterances to be analyzed by the jury. Then the researcher put the utterances into tables to make questionnaires for the jury. The questionnaires are easy for the jury to answer and make it precise for the researcher to elicit accurate results, statistics and conclusions in percentage.

\subsubsection{The utterances}


The study contains a total of one hundred and sixty eight (168) utterances for the five participants or speakers. Then each jury member analyzes the one hundred and sixty eight utterance so we have a total amount of six hundred and seventy two (672). The utterances is chosen and divided in the first place by one of the jury "Kendra Macey". She listens to the audios and divided them into utterances to be analyzed by the jury.

The above explanation goes along with the broad aim of this research, i.e. to conclude something about how Bedouins or non native speakers in general express themselves and if they use intonation effectively and skillfully to communicate. The rest of this chapter focuses mainly on one of most effective tools of language, namely intonation.

\section{Theories of the analysis:}

\subsection{Crystal's Lexicon (1969):}

Crystal (1969) investigated the expression of attitude by asking people to perform a set of sentences in a way that expressed a particular attitude. The twenty attitudes that Crystal selected were: "haughty, puzzled, amused, pleased, questioning, worried, dismayed, disapproving, vexed, conspiratorial, impatient, satisfied, grim, excited, precise, angry, matter-of-fact, bored, irritated, apologetic" (Tench, 1996: 121). Yet, for Crystal's system to work, both prosodic and paralinguistic features are to be considered side by side. 


\subsection{Crystal's Lexicon (1975):}

Later, in Crystal (1975:38), another simpler attitudinal lexicon appeared, based mainly on seven tones occurring in both final and non-final tonics in sentences. These tones are: level, low rise, low fall, high fall, high rise, fall-rise, and rise-fall. In this case other prosodic and paralinguistic features are excluded.

A complete reference to the tones mentioned above and their meanings is given in the following table that is summed up by Dr. Marwa Eleleidy and was mentioned in her thesis.

\section{Crystal's System (1975)}

\begin{tabular}{|l|l|l|}
\hline Tone & $\begin{array}{l}\text { Position in } \\
\text { sentence }\end{array}$ & Descriptive Label \\
\hline Level & $\begin{array}{l}\text { Final tonic in } \\
\text { sentence }\end{array}$ & $\begin{array}{l}\text { Absence of emotional involvement, } \\
\text { which may be interpreted as sarcasm, } \\
\text { irony, boredom, etc. }\end{array}$ \\
\cline { 2 - 3 } & $\begin{array}{l}\text { Non-final tonic } \\
\text { in sentence }\end{array}$ & $\begin{array}{l}\text { Implication of routines-perhaps arising } \\
\text { out of the level tone in final position }\end{array}$ \\
\hline Low \\
rise & $\begin{array}{l}\text { Final tonic in } \\
\text { sentence }\end{array}$ & $\begin{array}{l}\text { Personal inconclusiveness-specific labels } \\
\text { used here are non-committal, } \\
\text { unaggressive, etc., which are a short } \\
\text { remove from polite, respectful, etc. } \\
\text { social openness- specific labels used } \\
\text { here are casual, friendly, persuasive, } \\
\text { etc. and (with appropriate kinesic } \\
\text { accompaniment ) warning, grim, etc. }\end{array}$ \\
\cline { 2 - 3 } & $\begin{array}{l}\text { Non-final tonic } \\
\text { in sentence }\end{array}$ & Attitudinally neutral \\
\hline Low & $\begin{array}{l}\text { Final tonic in } \\
\text { fantence }\end{array}$ & Attitudinally neutral \\
\cline { 2 - 3 } & Non-final tonic & Personal definitiveness-specific labels \\
\hline
\end{tabular}


An Investigation of the Production of... العدد الثامن والثلاثون

\begin{tabular}{|l|l|l|}
\hline & in sentence & $\begin{array}{l}\text { used here are abrupt, insistent, etc. } \\
\text { unsociability- - specific labels being } \\
\text { cool, irritated, rude, etc. }\end{array}$ \\
\hline $\begin{array}{l}\text { High } \\
\text { fall }\end{array}$ & In any position & $\begin{array}{l}\text { Definite emotional commitment - } \\
\text { specific labels being emphasis, surprise, } \\
\text { warmth, selection depending very much } \\
\text { on kinesic accompaniment. }\end{array}$ \\
\hline $\begin{array}{l}\text { High } \\
\text { rise }\end{array}$ & In any position & $\begin{array}{l}\text { Definite emotional inquiry - specific } \\
\text { labels being query, puzzlement, } \\
\text { surprise, etc. }\end{array}$ \\
\hline $\begin{array}{l}\text { Fall- } \\
\text { rise }\end{array}$ & In any position & $\begin{array}{l}\text { Uncertain outcome - doubt, hesitation, } \\
\text { etc., leading to suspicion, threatening, } \\
\text { etc. }\end{array}$ \\
\hline $\begin{array}{l}\text { Rise- } \\
\text { fall }\end{array}$ & In any position & $\begin{array}{l}\text { Definitive outcome - impressed, } \\
\text { satisfied, smug, etc., or the reverse, } \\
\text { depending on kinesic accompaniment }\end{array}$ \\
\hline
\end{tabular}

\subsection{Peter Roach (2004/2009):}

Some functions of English tones is presented as stated in Roach(2009) "We will now see if it is possible to state in what circumstances the different tones are used within the very limited context of the words 'yes' and 'no' said in isolation. We will look at some typical occurrences; no examples of extra pitch height will be considered here, so the examples should be thought of as being said relatively low in the speaker's pitch range."

\section{Falllyes\no}

This is the tone about which least needs to be said, and which is usually regarded as more or less "neutral". If someone is asked a question and replies lyes or \no it will be understood that the question is now answered and that there 
is nothing more to be said. The fall could be said to give an impression of "finality".

The main scope of the study is the attitudinal function of intonation via tone from a perceptual point of view. Thus, records are analyzed quantitatively and qualitatively, and then generalizations are made. Tables and graphs are used to sum up similarities and differences and a conclusion is given about the general attitude Bedouins adopt and the misunderstandings that occur according to the results of the study.

As outlined earlier in the study, Intonation is the major focus used (among other tools) of language to deliver hidden messages like feelings and attitudes. The usage of a tone instead of another may cause misunderstanding or confusion between the participants in the conversation. The analysis of the data is from an attitudinal point of view in the light of perceptual phonology. As the saying goes, it's not what you say but it's how you say it.

Regarding perceptual phonology, the data is collected and analyzed from a perceptual point of view. The data is collected by recording audios for the participants either speaking alone or in a conversation - of course after their consent for the sake of honesty- then writing down the script of what was said. The audios are then divided into utterances by the aid of native speakers specialized in English language. Those utterances are made in the form of a questionnaire and given to the jury to analyze. The jury 
consists of five highly educated native speakers specialized in English language. The participants of the jury listen to the utterances and fill into the questionnaire, they recognize the tones the Bedouin speakers produce and mention what feelings and attitudes they perceive as a hearer.

As stated by Roach (1992), "The attitudinal use of intonation is something that is best acquired through talking with and listening to English speakers." (p. 169). The use of different tones, when producing or when uttering the same word, delivers different messages or different attitudes to the listener. Tones play with the inferred meaning or the deep meaning of words. The main concern of the study is to investigate the intonational patterns used by Bedouins speaking English language, do they use the correct tone to express their emotions and attitudes and if there is any kind of misunderstanding resulting from the misuse of tones.

In this section the researcher analyze the data collected and tries to answer the research questions. The recorded data for Bedouin speaking English language is divided into several utterances for each speaker or participant. Firstly, some samples of the data are analyzed then a detailed statistical analysis for tones and attitudes is presented. Data is analyzed qualitatively and quantitatively in this section.

\subsection{The qualitative analysis:}


In this part the researcher presents some extracts from the script and analyzes them in the light of the results of the questionnaires that the jurors filled. Extracts from every participant is presented followed by the utterance in specific. Each utterance is analyzed fully according to the opinion of all the jury members.

\section{Mariam:}

Extract number one:

"**my name is Mariam and .. and I live in Dahab and $\ldots$

*Okay so tell me about the vacation

**el 3eed

*Vacation Agaza

**el agaza

*Yes

**eh ... eh ... like I go to sea and we take trip with us with my friends and with my family... and ... we go to masbat and like and we sit with us and go and go to home to to grandma

*Ahuh 
**and bs

*okay, so what do you like about the school

**eeeh... I like to school they like I can be berfect (perfect) and I like school and I like writing and reading

* okay and in your day normally when you're not at school what do you do ?

**I sit in my home like with my family with my sisters and fathers"

The previous script of Mariam is divided into some utterances. In utterance number 1: "my name is Mariam" The five members of the jury perceive five different tones.

Kendra perceives the tone of this utterance as a risingfalling tone. Bridget and Susan perceive the tone of the utterance as a rising tone. Johania perceives the tone of the utterance as a rising-falling tone. Anna perceives the tone of the utterance as a level tone.

Regarding the attitude recognition; Kendra elicits the following attitudes (bashful and finality). Bridget and Susan understand that Mariam is shy. Johania elicits that the speaker is hesitant. Anna elicits that the speaker is pleased.

From the previous observation of the results; the five jurors perceive different tones and they all understand different attitudes or emotions. Some agreed on the fact that 
the speaker is (bashful or shy) and both are close in meaning while others felt that the speaker is hesitant and another juror think the speaker is pleased. So regardless of the different tone recognition all jurors noticed different attitudes with a wide range of emotions and feelings swinging from shyness to happiness and hesitancy. So a wide range of feelings or attitudes with opposite meanings can be understood by native speakers listening to the same utterance.

The previous script of Mariam is divided into some utterances. In utterance number 2: "and .. and I live in Dahab" The five members of the jury perceive five different tones.

Kendra perceives the tone of this utterance as a risingfalling tone. Bridget and Susan perceive the tone of the utterance as a falling tone. Johania perceives the tone of the utterance as a rising tone. Anna perceives the tone of the utterance as a rising tone.

Regarding the attitude recognition; Kendra elicits finality as the expressed attitude by the speaker. Bridget and Susan understand that Mariam is being (factual or shy). Johania elicits that the speaker is questioning. Anna elicits that the speaker is pleased.

From the previous observation of the results; the five jurors perceive different tones and they all understand different attitudes or emotions. All the members of the jury understand different attitudes and emotions. So regardless of 
the different tone recognition all jurors noticed different attitudes with a wide range of emotions and feelings swinging from finality to being factual or shy to questioning to being pleased. So a wide range of feelings or attitudes with opposite meanings can be understood by native speakers listening to the same utterance. Most notably here is an utterance like "and .. and I live in Dahab" the speaker is sure that she lives in Dahab city while one of the jurors understand that she is questioning! Here the use of the rising tone according to Johania's analysis lead her to feel that the speaker is questioning -while the girl is sure that she lives in Dahab and there is no way that she is questioning- because according to Peter Roach and David Crystal the rising tone indicates inquiry or is used for inquiries. So the misuse of tones can lead to misunderstanding in communication.

The previous script of Mariam is divided into some utterances. In utterance number 12: "with my family with my sisters and fathers" The five members of the jury perceive different tones.

Kendra perceives the tone of this utterance as a falling tone. Bridget and Susan perceive the tone of the utterance as a rising tone. Johania perceives the tone of the utterance as a rising-falling tone. Anna perceives the tone of the utterance as a level tone.

Regarding the attitude recognition; Kendra elicits incompleteness and uncertainty as the expressed attitude by the speaker. Bridget and Susan understand that Mariam is 
pleased. Johania elicits that the attitude is (a matter of fact). Anna elicits that the speaker is pleased.

From the previous observation of the results; the five jurors perceive different tones and they all understand different attitudes or emotions. All the members of the jury understand different attitudes and emotions. So regardless of the different tone recognition all jurors noticed different attitudes with a wide range of emotions and feelings some perceive that the speaker is uncertain or have more to say while others feel that she is pleased or saying a fact. So a wide range of feelings or attitudes with opposite meanings can be understood by native speakers listening to the same utterance. Most notably here is one of the jurors recognize a falling tone and understands an uncertain or incomplete attitude. Here the use of the falling tone according to Kendra's analysis lead her to feel that the speaker is uncertain or have more to say, even though according to Peter Roach and David Crystal the falling tone indicates finality or is used for when there is nothing more to be added. In addition to, the falling- rising tone is used to express the uncertainty and incompleteness attitudes. So the misuse of tones can lead to misunderstanding in communication.

\subsection{The quantitative analysis:}

In this part of chapter three the researcher presents the statistical tables that sum up the results of the questionnaires. In addition to graphs that shows the 
An Investigation of the Production of... العدد الثامن والثلاثون

statistical graphs that shows percentages and frequency of occurrence of each tone and attitude mentioned in the study. The analysis and comments follows each table, graph or figure.

\subsubsection{All tones recognized:}

\begin{tabular}{|l|l|l|}
\hline Row Labels & Count of Tones & Percentage \\
\hline Falling & 101 & $15.03 \%$ \\
\hline Falling to level & 7 & $1.04 \%$ \\
\hline Falling to Rising & 6 & $\mathbf{0 . 8 9 \%}$ \\
\hline Level & 163 & $\mathbf{2 4 . 2 6 \%}$ \\
\hline level to falling & 3 & $\mathbf{0 . 4 5 \%}$ \\
\hline Level to Rising & 14 & $\mathbf{2 . 0 8 \%}$ \\
\hline Rising & 258 & $\mathbf{3 8 . 3 9 \%}$ \\
\hline Rising - Falling & 97 & $14.43 \%$ \\
\hline Rising to Level & 12 & $1.79 \%$ \\
\hline rising-falling-rising & 11 & $1.64 \%$ \\
\hline Grand Total & 672 & $100.00 \%$ \\
\hline
\end{tabular}

(Table number1)

This table shows the count of all tones recognized by the jury. Ten tones are perceived by the jurors. From the total count of 672 utterances being analyzed 258 utterances or tone units are recognized as rising. The total of 163 utterances is recognized level. The total of 101 tone unit is recognized falling. The total of 97 utterances is recognized rising-falling. Then the least tones recognized by the jurors are level-rising mentioned 14 times, rising-level mentioned 12 times, rising-falling-rising mentioned 11 times, falling- 
level mentioned 7 times, falling-rising mentioned 6 times and finally level-falling mentioned 3 times.

From the previous observations; Bedouins as nonnative English speakers use the most in their speech the rising tone, the level tone, the falling tone and the risingfalling tone. On the other hand they use the least in their speech the level-rising tone, the rising-level tone, the risingfalling-rising tone, the falling-level tone, the falling-rising tone and the level-falling tone. Most importantly, the jury perceived tones that are not mentioned by Peter Roach or David Crystal like the rising-falling-rising for example.

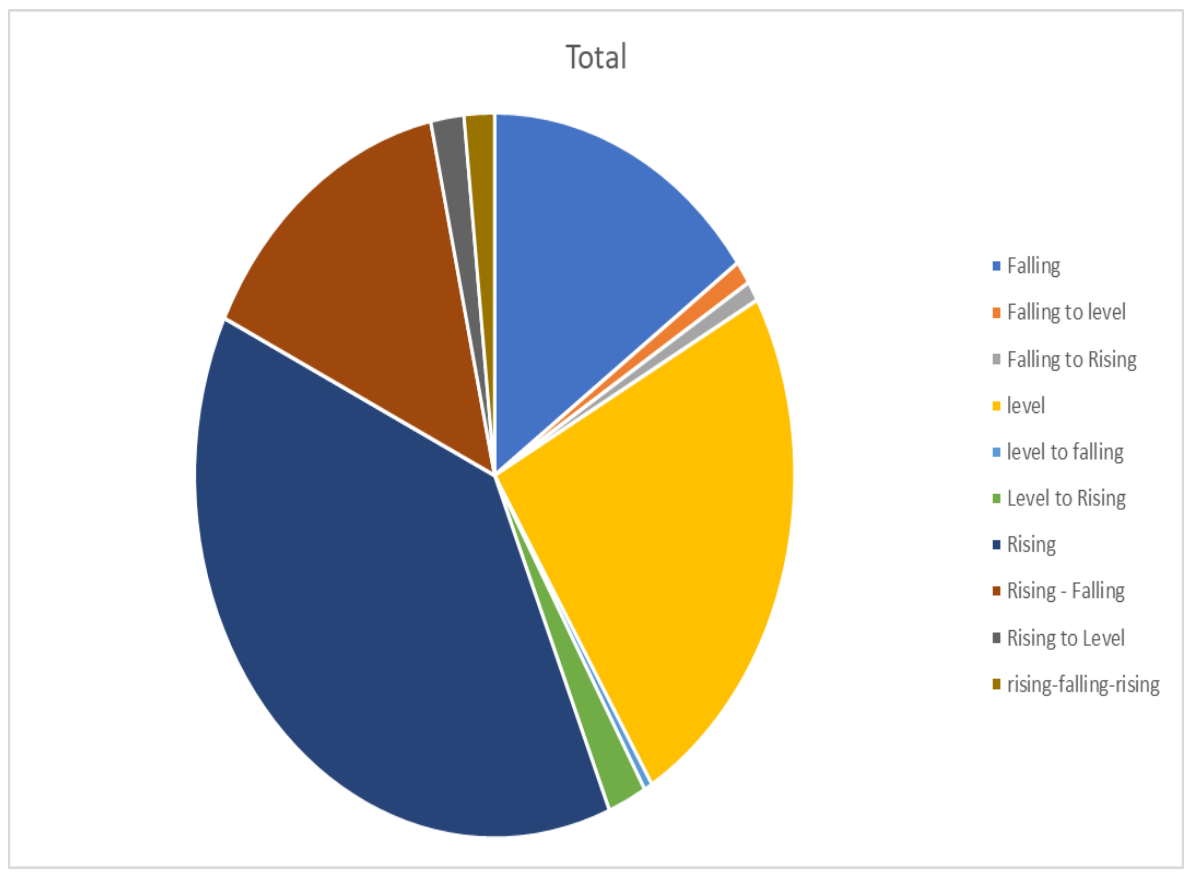


The previous charts show clearly the variation in the percentage of tone usage or the frequency of occurrence of tones in non-native speaker's speech according to what the native speakers (the jury members) perceive.

It is generally observed that being factual of stating a matter of fact is the most expressed attitude with the highest percentage. This indicates that Egyptian South Sinai Bedouins -as an example of non native speakers- are speaking the truth and represent honesty as a general image. Being attitudinally neutral, happiness (being pleased), emphasis on their point of view, pride, explanations, and confidence are the attitudes expressed in the second place. This indicates that Bedouins are cheerful and determined which shows clearly on their speech.

\section{Conclusion:}


- The excited attitude is expressed by the use of a rising-falling tone according to Peter Roach and David Crystal. While what is apparent is that the native speaker perceives the tone as level and yet understood the feeling/emotion or attitude as the speaker being excited.

- The presence of unmentioned tones before, the risingfalling-rising is a tone noted and recognized by the native speakers of English language but not included in the five types of tones mentioned by Peter Roach or in the table of tones of David Crystal.

- In an utterance like "and .. and I live in Dahab" the speaker is sure that she lives in Dahab city while one of the jurors understand that she is questioning! Here the use of the rising tone according to Johania's analysis lead her to feel that the speaker is questioning -while the girl is sure that she lives in Dahab and there is no way that she is questioningbecause according to Peter Roach and David Crystal the rising tone indicates inquiry or is used for inquiries. So the misuse of tones can lead to misunderstanding in communication.

- It is noted that in some cases one of the jurors recognizes a falling tone and understand an uncertain or incomplete attitude. Here the use of the falling tone according to Kendra's analysis in one of the utterances as an example lead her to feel that the 
speaker is uncertain or have more to say, even though according to Peter Roach and David Crystal the falling tone indicates finality or is used for when there is nothing more to be added. In addition to, the falling- rising tone is used to express the uncertainty and incompleteness attitudes. So the misuse of tones can lead to misunderstanding in communication.

- In some cases of misuse of intonational patterns; Johania suggests that the tone of the utterance is a rising tone and the expressed attitude is stating a fact; while according to Peter Roach and David Crystal the use of the falling tone indicates or expresses finality or stating facts.

- Bedouins as non-native English speakers use the most in their speech the rising tone, the level tone, the falling tone and the rising-falling tone. On the other hand they use the least in their speech the level-rising tone, the rising-level tone, the rising-falling-rising tone, the falling-level tone, the falling-rising tone and the level-falling tone. Most importantly, the jury perceived tones that are not mentioned by Peter Roach or David Crystal like the rising-falling-rising for example.

- From the observation of the frequency of occurrence of each attitude expressed by the falling tone it is noticed that Bedouins -as an example of non native speakers- use the falling tone to express the neutral 
attitude and when stating a matter of fact the most. While it is used also to express other feelings and attitudes that -according to Peter Roach and David Crystal- is supposed to be expressed using other tones; for example thinking is supposed to be expressed using the falling-rising attitude.

- It is also observed that attitudes like emphasising and stating a matter of fact are frequently expressed by Bedouins using the falling-level tone. In addition to the recognition of the falling-level tone by the jury which was not mentioned or categorized by Peter Roach. Meanwhile, the falling-rising tone is supposed to be used to express uncertainty -as mentioned before by Peter Roach- not the falling-level tone.

- It is observed that Bedouins express sadness, being thoughtful and uncertainty using the falling-rising tone in accordance with what Peter Roach and David Crystal stated. While they used the falling-rising tone to express happiness, being factual and stating a matter of fact with a higher percentage and this is not in accordance with what the scholars stated.

- From the common misuses of the intonational patters; it is noted that the level-rising is used by Bedouins mostly to express emphasis, happiness and stating facts. It is supposed that the rising-falling is used to express strong emotions and the falling tone to state facts. 
- The new tones recognised by natives or the jury may be a result of language change as for example pidgins and creoles.

- The mistakes in pronunciation or word choice may cause hesitancy and lack of confidence to be recognized as the perceived attitude of the speaker.

\section{References}

Crystal, D. \& Davy, D. (1975). Advanced Conversational English. London: Longman.

Crystal, D. (1975). 'Prosodic features and linguistic theory.' In D.

Crystal, The English tone of voice. London: Edward Arnold.

Crystal, D. (1969). Prosodic Systems and Intonation in English. Cambridge: Cambridge University Press.

Gussenhoven, C. \& Riad,T. (2007). Tones and Tunes. Second Edition. Mouton de Gruyter: Berlin. New York

Gussenhoven, C.(2004). The phonology of Tone and Intonation. Cambridge: Cambridge University Press. 
Halliday,M. A. K. (2003). On Language and linguistics. Continuum: London. New York.

Hirst, D. \& Cristo, Di. A. (1998). Intonation systems. A survey of twenty languages. Cambridge: Cambridge University Press.

Ladd, Robert.(2008). Intonational phonology. Cambridge: Cambridge University Press.

Roach,P. (1998). English Phonetics and Phonology. Cambridge: Cambridge University Press.

Tench, P. (1996). The Intonation Systems of English. London: Cassell Academic.

Uldall, E. (1964). Dimensions of meaning in Intonation. London:Longman.

Tench, P. (2005). Intonation and categories of meaning. Cardiff University, Wales, UK.

Ladefoged and Johnson.2011.6th ed.A course in phonetics

[Gussenhoven,_Carlos,_Riad,_Tomas]_Tones_and_Tu nes(Bookos.org)

[Carlos_Gussenhoven]_The_Phonology_of_Tone_and _Int(Bookos.org)

Peter.Roach_1998_English.Phonetics.and.Phonology_ $2 \mathrm{e}$ 
An Investigation of the Production of... العدد الثامن والثلاثون

Cruttenden, A. (1986). Intonation. Cambridge:

Cambridge University Press. 